\title{
EL ESCENARIO CARCELARIO Y LAS REFORMAS A LA NORMATIVIDAD PENITENCIARIA EN EL ESTADO DE SAN LUIS POTOSÍ. ¿HAN SIDO SUFICIENTES ANTE LA CRISIS DE LOS PENALES EN LA ENTIDAD?
}

\author{
A glimpse inside imprisonment and prison conditions in San Luis Potosí, ¿does the \\ legislative reform face the actual crisis?
}

Paola Iliana DE LA ROSA RORÍGUEZ ${ }^{1}$

\begin{abstract}
Sumario:
I. Consideraciones iniciales del Ius puniendi y el encarcelamiento. II. Condiciones del sistema penitenciario mexicano. III. El panorama penitenciario potosino y su normatividad carcelaria. IV. Derecho a la salud y a la alimentación sana. V. El trabajo, la educación y deporte en los centros de reinserción. VI. Autogobierno, riñas y motines. VII. Reformas al sistema penitenciario mexicano. VIII. Reforma legislativa en materia de Ejecución Penal en México. IX. Desafíos en la normatividad punitiva. X. Conclusiones. XI. Bibliografía.
\end{abstract}

Resumen. El presente artículo hace referencia a la crisis carcelaria que se vive en México, haciendo énfasis en el estado de San Luis Potosí. Posteriormente el trabajo describe y revisa las reformas legislativas que se han generado en materia penitenciaria en el estado potosino en respuesta a la crisis carcelaria en especial analizando con este propósito la inclusión de la figura del juez de ejecución, su impacto, sus atribuciones y su coordinación con otros poderes y centros de reinserción.

Palabras clave. cárcel, pena privativa de libertad, reo, sistema penitenciario, reinserción social

Abstract.This article presents the harsh prison conditions in Mexico, emphasizing the issue in San Luis Potosí. At the same time, this paper mentions recent legislative reforms regarding the prison system and the new role of the judge executing judgments, his functions and his connection with state and jail authorities.

*Profesora investigadora de la Facultad de Derecho "Abogado Ponciano Arriaga Leija" de la Universidad Autónoma de San Luis Potosí.

Key words. jail, imprisonment, inmate, prison system, social integration

\section{CONSIDERACIONES INICIALES DEL IUs puniendi Y EL ENCARCELAMIENTO}

En la actualidad los centros de reclusión son espacios de opresión, abandono y autogobierno en los que los privados de su libertad pierden su calidad de humanos, son olvidados y su

\footnotetext{
${ }^{1}$ Profesora investigadora de la Facultad de Derecho "Abogado Ponciano Arriaga Leija” de la Universidad Autónoma de San Luis Potosí.
} 
diaria convivencia, entre guardias y sentenciados, los insensibiliza y los incentiva a retornar a conductas ilícitas.

Cito a Mariano Ruiz Funes quien tiene la siguiente expresión sobre mencionados centros:

La prisión contiene, pero no corrige. Cumple con un fin que no es un fin. Constituye un obstáculo negativo, pero no llena ninguna función positiva. Mantiene al hombre apartado de la sociedad, pero no crea en él aquellas disposiciones sociales cuya carencia puso de relieve el delito. Quiere ser un monólogo que haga brotar, por el remordimiento, las aguas purificadoras de la catarsis y resulta un diálogo que engendra nuevos impulsos criminales en el prisionero. Lo degrada o lo embrutece. Lo devuelve estigmatizado, sin más opción que la reincidencia. ${ }^{2}$

Es cierto que el Estado ha de velar por los intereses de la sociedad que lo forma y que es una obligación del primero preservar la seguridad y abatir la criminalidad, pero también resulta incuestionable que la sociedad misma apreciará, sobre todo, la prevención que se haga del delito a través de disminuir las condiciones que favorecen la comisión del ilícito,-como el desempleo, la indigencia y el limitado acceso a la educación por ejemplo- así como acentuando las posibilidades de captura de los infractores.

La represión ha demostrado no ser efectiva y más allá de enfrentar la delincuencia, fomenta excesos por parte de los cuerpos policíacos que en forma exigua respetan los derechos humanos. La simple agudización de la pena de prisión no es el camino apropiado para encarar el delito sobre todo cuando ésta provoca violaciones a los derechos fundamentales, en especial de los indiciados que resultan legalmente inocentes. A pesar de ello, el Estado se ha centrado en la represión a través del encarcelamiento y ha permitido que prevalezcan la dureza y las malas condiciones con las que el interno permanece privado de su libertad.

Pues bien, el derecho penal y con él el derecho punitivo están en constante evolución; se han abandonado viejos arquetipos y en esta tesitura han surgido nuevas corrientes ideológicas que consideran que el conjunto de delitos, penas, tribunales y prisiones son el último recurso de control social en una sociedad democrática. Las amenazas y los castigos son instrumentos punitivos que deben prevalecer en sociedades autoritarias que no buscan otros medios para encauzar la conducta de los individuos, ${ }^{3}$ no en sociedades con apego al estado de derecho. En este sentido, el derecho penitenciario debe estar limitado por las garantías procesales, garantías jurisdiccionales y garantías de ejecución penal, las cuales derivan del principio de legalidad.

Algunos límites al uso indiscriminado de la prisión se presentan cuando el derecho penal entra en contacto con otras áreas del derecho como el derecho Constitucional y los principios que de éste emanan, incluyendo los derechos fundamentales consagrados por la Ley Fundamental de cada país así como los contenidos en los tratados internacionales. ${ }^{4}$ La concepción moderna es que el Derecho Penal debe ser la última ratio legis que se utilice para mantener el orden público. Más que incrementar delitos y penas, la inclinación debe ser des-

\footnotetext{
2 RUIZ FUNES, Mariano, La Crisis de la Prisión, Montero Editor, La Habana, 1949, pp. 7-8.

3 GARCÍA RAMIREZ, Sergio, "En torno a la seguridad pública”, en PEÑALOZA, Pedro José y GARZA SALINAS, Mario, (coordinadores), Los desafíos de la seguridad pública en México, Universidad Iberoamericana, UNAM, PGR, México, 2002, p. 81.

4 Idem.

CienCIA JuRídica. Departamento de Derecho. División de Derecho, Política y Gobierno, Universidad de Guanajuato - Año 5, No. 9, 2016
} 
criminalizar ciertas conductas, ${ }^{5}$ respetar los derechos humanos de los internos que no por ello pierden su calidad de seres humanos. Se ha considerado que en un estado de derecho, tanto el inculpado como la víctima son sujetos del proceso y titulares de derechos fundamentales. Por ello hay tendencias garantistas del derecho penal que lo llevan hacia una humanización de las consecuencias del delito y cuyas normas jurídicas han superado la crueldad de las penas corporales. Estas corrientes ven en la prisión un mecanismo de exclusión y de supresión al principio de la dignidad humana y perciben que la pena de prisión lejos de reparar el daño a la víctima, lo aleja de estar en posibilidades de hacerlo y contrariamente a esperar una reinserción del individuo cuando haya cumplido su encierro, lo involucra con reclusos de los cuales aprenderá nuevas formas de cometer ilícitos. Las políticas de algunos países latinoamericanos han sido de incorporar prisiones abiertas, libertad con monitoreo electrónico o bien apoyo pos penitenciario.

\section{CONDICIONES DEL SISTEMA PENITENCIARIO MEXICANO}

La realidad del sistema penitenciario en México es que a los detenidos, procesados y condenados, con excepción del derecho de defensa, no les son reconocidos efectivamente los derechos consagrados en la Carta Magna y quedan sometidos a los abusos de los funcionarios de la administración carcelaria. Ahora bien, la concepción de que los presos no tienen ningún derecho es antigua y errónea. En épocas primitivas el delincuente era expulsado de su grupo social lo que conllevaba prácticamente a su muerte civil. Aunado a ello, el interno se encontraba en un estado de indefensión, sin ningún derecho y más que un ser humano, era prácticamente un objeto. Aunque esta situación se modifica con los positivistas italianos quienes consideran que la privación de la libertad debe tener una función resocializadora, ${ }^{6}$ el escenario en el que viven los reclusos, al menos en nuestro país sigue siendo deplorable e indignante. La situación carcelaria de México es precaria. A manera de ejemplo, la vigilancia de los internos está en las manos de gente que no tiene la capacitación y preparación para proporcionarles el trato adecuado; por otra parte, la asistencia médica, si la tienen, es carente, pocos son los que acceden a la instrucción y muchos menos los que reciben ayuda espiritual o religiosa. Se carece de instalaciones apropiadas y suficientes para los internos que inclusive son ineficientes para distribuir a la población femenil, a los grupos vulnerables e inimputables. Algunos internos son víctimas de altercados ocurridos en el interior de las celdas, otros tantos agonizan y mueren como resultado de los mismos. ${ }^{7}$ Una situación agravante en México es la sobrepoblación carcelaria abrumadora que provoca que los internos vivan en condiciones de hacinamiento y durante el tiempo de espera que sufren en dichos centros, aprenden nuevas formas de comisión de crímenes que utilizarán una vez alcanzada su libertad. Dicha situación a su vez genera riñas, motines, fugas, suicidios, tráfico de drogas y armas solventadas por la corrupción de la administración carcelaria que permite la venta

\footnotetext{
${ }^{5}$ Lo cual se realiza en un intento por terminar con la práctica de reaccionar: "todos contra todos" y recordando que el infractor no pierde su carácter de persona y con ello sigue poseyendo sus derechos fundamentales.

${ }^{6}$ COTE-BARCO, Gustavo, La necesidad de la pena, reflexiones a partir de los artículos 3 y 4 del código penal colombiano. Revista del Instituto de la Judicatura Federal, Bogotá, no.114, julio-diciembre 2007, p. 199.

7 BARROS LEAL, César, La Ejecución Penal en América Latina a la luz de los Derechos Humanos. Viaje por los senderos del dolor, Editorial Porrúa, Naciones Unidas Ilanud, Facultad de Derecho UNAM. México 2009, p. 45.
} 
de privilegios y el autogobierno. Esta misma sobrepoblación ${ }^{8}$ hace prácticamente imposible practicar programas de readaptación a los internos para distanciarlos de la criminalidad y la adicción a las drogas. Mencionado inconveniente obedece a siete factores principales: el aumento de la criminalidad, especialmente el secuestro y los robos con violencia, el rezago judicial ya que la lentitud de los procesos judiciales no hace posible que casi el $50 \%$ de la población carcelaria mexicana sea sentenciada, la sobreutilización de la pena de cárcel y el endurecimiento de las penas, la aplicación de medidas administrativas de modo arbitrario, la insuficiencia de espacio en las cárceles y la renuencia de aplicar penas alternativas. ${ }^{9}$ Añadiría que esta crisis proviene también del poco presupuesto de las instituciones encargadas de administrar la justicia. A esta problemática se suman la propagación de enfermedades tales como sífilis, tufus, sarampión, varicela, hepatitis, tuberculosis y otras más en razón de que no son atendidas propiamente y de la falta de higiene presente en centros carcelarios. Barros puntualiza que los alimentos deberían ser balanceados e higiénicos, pero hay relatos de comida descompuesta que produce enfermedades. ${ }^{10}$ Las prisiones son lugares donde se compra el acceso a determinadas áreas, la ubicación en lugares más cómodos o más seguros, las llamadas telefónicas o las cobijas. Además hay restricciones para obtener la libertad bajo fianza y beneficios de libertad anticipada.

Las condiciones de vida de las mujeres reclusas son de desigualdad y representan un grupo vulnerable careciendo de las mismas oportunidades de los hombres en cuanto el acceso a ciertos derechos. Los indígenas, de los cuales se estima hay cerca de 7,00o en los penales y que se encuentran en su mayoría en Oaxaca y Veracruz no tienen la asistencia de intérpretes o traductores. En lo tocante a los discapacitados, éstos no cuentan con equipos especiales para su condición física especial. ${ }^{11}$ Como se observa, subsiste el marcado entorno de crisis penitenciaria en el que el interno pierde muchos derechos inherentes a su condición de ser humano. Ahora bien, la ideología penitenciaria ha evolucionado y la concepción ahora es que el interno no pierde la calidad de ser humano y sigue conservando casi todos sus derechos. Tiene sentido hablar de un derecho penal como dijera Luna, "racionalmente limitado" y garantista en donde se respeten los principios contenedores del "ius puniendi" que contemplan la reacción contra el delito y de seguridad jurídica y de legalidad en general. ${ }^{12}$ Es aquí en donde el infractor, sujeto del derecho penal, es visto como un ser humano, como una persona titular de derechos y aunque es el sujeto pasivo de la relación que tiene con el Estado para efectos del derecho penal, tiene facultad para actuar en su propio beneficio. Todos aquellos derechos del individuo, que no forman parte del contenido de la pena, le deben ser reconocidos, no obstante su estado detentivo, es decir, no obstante se trata de una persona privada de su libertad. Es entonces, ante estas nuevas tendencias y ante la falta de respuestas adecuadas del gobierno para afrontar este grave problema,- que impide que el carácter humanista del penitenciarismo mexicano pueda ser siquiera pronunciado como una frase posible,- que se ha considerado benéfico terminar con la discrecionalidad de la autoridad administrativa encargada de la ejecución de penas.

\footnotetext{
8 El 6 de julio del 2006 el periódico Le Monde dio a conocer que la sobrepoblación carcelaria de Brasil y México están a la cabeza y que provocan hacinamiento, promiscuidad, tensiones, ociosidad, además de dificultar las funciones y los servicios básicos como el trabajo, la educación, la recreación, la salud, la alimentación, la asistencia legal y la seguridad.

${ }^{9}$ BARROS LEAL, César, op. cit., nota 8, p. 64.

${ }^{10}$ Idem.

${ }^{11}$ Ibidem, p. 131.

${ }^{12}$ LUNA CASTRO, José, op. cit., nota 3, p. 22.

Ciencia JuRídica. Departamento de Derecho. División de Derecho, Política y Gobierno, Universidad de Guanajuato - Año 5, No. 9, 2016
} 


\section{EL PANORAMA PENITENCIARIO POTOSINO Y SU NORMATIVIDAD CARCELARIA}

El sistema carcelario del Estado de San Luis Potosí no queda exento a los problemas que se han descrito en páginas anteriores. Actualmente hay más de 3,200 reos en el Estado y más de cien menores en conflicto con la ley penal con edades que varían desde los 14 a los 18 años. ${ }^{13}$ La distribución de centros penitenciarios en el Estado está dividida en Centros Estatales de Reinserción Social y Centros Distritales de Reinserción Social los cuales están ubicados en los 13 distritos judiciales que a continuación se mencionan:

\section{CEREDIS}

1. Santa María del Río

2. Salinas

3. Venado

4. Guadalcazar

5. Cerritos

6. Ciudad del Maíz

7. Cárdenas
CERESOS

1.- San Luis Potosí

2.- Centro de Internamiento Juvenil

3.- Matehuala

4.- Rioverde

5.- Ciudad Valles

6.- Tamazunchale

7.- Tancanhuitz

\section{UBICACIÓN DE CEREDIS Y CERESOS EN SAN LUIS POTOSI ${ }^{* *}$}

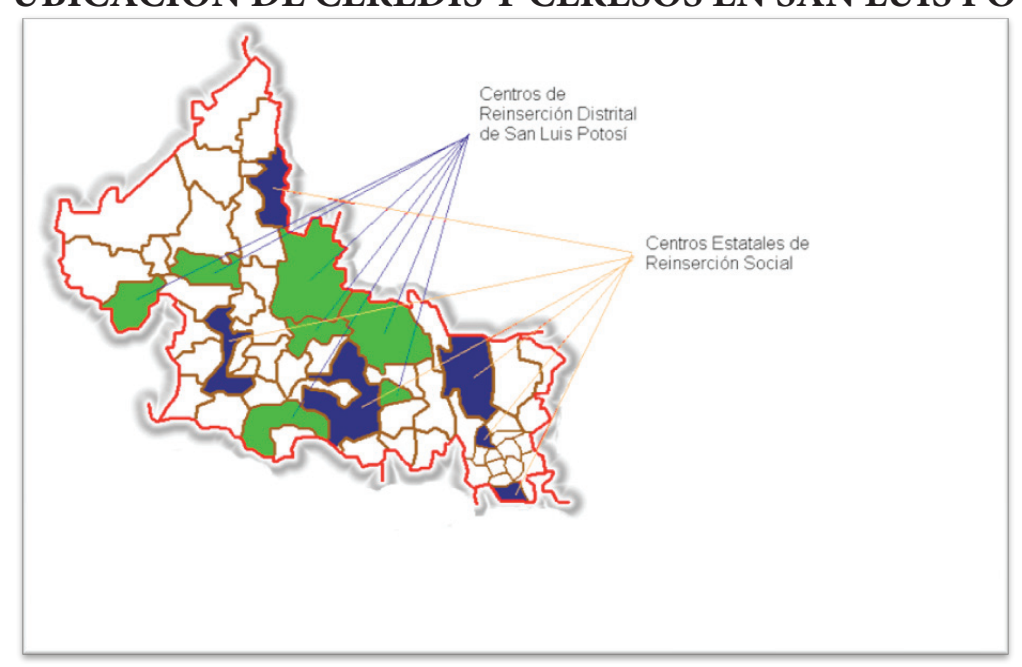

${ }^{* *}$ Tabla proporcionada por la Comisión Estatal de Derechos Humanos de San Luis Potosí.

Los Centros de Reclusión Distrital son centros de detención en los que permanecen las personas cuyo proceso penal aún no concluye, es decir que no han recibido sentencia definitiva. Estos Centros se encuentran bajo la administración y mantenimiento de los respectivos municipios y los Centros de Reinserción Social tienen aporte del Gobierno del Estado. Todos alojan internos y procesados del orden común, bajo la supervisión del Ejecutivo del Estado a través de la Dirección General de Prevención y Readaptación Social. La población interna

\footnotetext{
${ }^{13}$ Información proporcionada por la Secretaría de Seguridad Pública. Septiembre del 2014.
} 
al ser sentenciada es trasladada a Centros de Reclusión que le corresponda, conforme a la cercanía del municipio de donde son originarios.

Un dato relevante proporcionado por la Tercera Visitaduría General de la Comisión Estatal de Derechos Humanos es que en los CERESOS del interior del Estado la queja más recurrente -a dicho de la población interna-, versa sobre "el desconocimiento de su situación jurídica, el estado de su proceso penal y gestiones sobre atención médica, audiencia, visitas familiares y traslados voluntarios para ser diligenciados ante la autoridad penitenciaria."14

En lo tocante a la infraestructura carcelaria, y no obstante que la Ley del Sistema Penitenciario de San Luis Potosí ${ }^{15}$ señala que las instalaciones del centro penitenciario deben de proveer seguridad al interno por parte de los custodios, salubridad en los espacios, enfermerías, ambiente propicio para la reinserción, dormitorios suficientes, patios de descanso, centros educativos, talleres de recreación, bibliotecas, auditorios, canchas deportivas e industria penitenciaria, según datos de la Secretaría de Seguridad Pública, en los CEREDIS existe sobrepoblación penitenciaria puesto que fueron construidos sin realizar un estudio a conciencia sobre el aumento de los índices delincuenciales.16 La mayoría de estos recintos carcelarios se encuentran ubicados en el traspatio de las presidencias municipales en los que se reconoce el autogobierno, el tráfico de drogas y alcohol, la corrupción y la falta de seguridad.

En efecto, los CERESOS como el de San Luis Potosí, Matehuala y Ciudad Valles cuentan en su mayoría con mencionadas instalaciones. Ahora bien, de acuerdo a la investigación realizada, los CEREDIS no reciben suficiente apoyo por parte del personal de los Ayuntamientos ni de la Dirección General de Prevención existiendo una carencia de fondos para la infraestructura y operatividad de estos Centros. A manera de ilustración, en algunos CEREDIS del estado no se cuenta con extintores, salida de emergencia, biblioteca, médicos, área de Psicología o áreas verdes.

Parte fundamental en todo centro de reclusión o reinserción es que existan áreas adecuadas para la estancia del interno, así lo estipula la Ley del Sistema Penitenciario en el estado de San Luis Potosí y el Reglamento Interno para los Centros de Reclusión Distrital en el sentido de que los internos estén divididos por su sexo, edad y grado peligrosidad. No obstante, en el Centro de Reinserción Social de la capital, al no haber una división entre sentenciados y procesados, cuando se satura la sección de procesados, los internos son trasladados a la sección de sentenciados. Por mencionar otro ejemplo, en el CEREDI de Santa María del Rio, no se puede dar cabal cumplimiento a la norma jurídica porque no hay espacio para hacer tales divisiones. Esta carencia de áreas separadas trae por consecuencia, entre otras, que las personas en la senectud, acrecienten problemas de esquizofrenia, además de que personas que fueron condenadas por haber cometido delitos graves como homicidio o violación convivan con individuos que fueron sentenciados por delitos menores o primo delincuentes.

En la capital del estado son muy pocos custodios para los 1800 internos. Existen tres grupos de custodios en cada turno, hay tres turnos con 70 custodios cada grupo. Los internos tienen poco respeto por los custodios. Según datos proporcionados en el Centro Estatal de Reinserción de la capital potosina, en la zona femenil hay 36 estancias, con 3 camas cada una, en total hay 108 camas. En el tiempo de la realización de la entrevista había 97 internas y no

\footnotetext{
${ }^{14}$ De acuerdo al tercer informe de actividades 2011 de la Tercera Visitaduría General dentro de las primeras jornadas interinstitucionales para la atención de personas privadas de su libertad.

${ }^{15}$ Artículo 12 de la Ley del Sistema Penitenciario de San Luis Potosí publicada en el Periódico Oficial del Estado de San Luis Potosí el 18 de junio de 2011.

${ }^{16}$ Información proporcionada por la Secretaría de Seguridad Pública. Agosto del 2014. 
había problemas de espacio, sin embargo, en otras ocasiones, según menciona el personal, en una estancia con capacidad para 3 mujeres, llegan a ingresar a más internas. ${ }^{17}$

Otra situación digna de mencionar, que compromete la seguridad de los Centros, es la inexistencia de equipo antimotines, gases, escudos, chalecos antibalas y cascos. Algunos CEREDIS del Estado han solicitado a los Ayuntamientos en los que están ubicados la compra de estos equipos sin haberlos recibido, esta autoridad se ha deslindado respondiendo que la cárcel pertenece al estado y no al municipio. En el Estado de San Luis Potosí, algunos distritos judiciales reciben y alojan a internos de más de tres municipios sin que estos contribuyan en la administración del mismo, haciendo complicada la situación económica para un solo municipio que llega a atender a más de la mitad de los internos de otro municipio. ${ }^{18}$

\section{DERECHO A LA SALUD Y A LA ALIMENTACIÓN SANA}

Los centros penitenciarios del estado son carentes de asistencia médica o hay pocas visitas de profesionales de la salud a las instalaciones penitenciarias estatales y distritales. De igual manera el medicamento es escaso y existe poca salubridad en los espacios. Ello contraviene el artículo 4 del Pacto Federal que establece el derecho que todo individuo tiene a la salud. La pena privativa de la libertad no tiene porqué representar un detrimento de este derecho y si una persona entra a un centro penitenciario y al obtener su libertad sale enfermo, entonces en forma adicional a su detención, el ser humano sufrió una depreciación de su condición física, por lo que el Estado no garantizó este derecho fundamental. En este respecto, cabe puntualizar que la prestación de la salud en los centros penitenciarios raramente es preventiva e irónicamente las drogas se obtienen con mayor facilidad que los medicamentos. ${ }^{19} \mathrm{El}$ desabasto de medicinas es aún más notable cuando se trata de internos con problemas mentales en evidente violación de los Principios para la Protección de los Enfermos Mentales y el Mejoramiento de la Atención de la Salud Mental. ${ }^{20}$ Tampoco hay suficiente suministro de medicinas para mujeres embarazadas, con menopausia, infecciones genitales y alteraciones al ciclo menstrual. ${ }^{21}$ En respuesta a este problema, se contempla que los centros de reinserción organicen campañas de medicina preventiva, vacunación y planificación familiar. Este es el escenario actual si bien es cierto que la ley del sistema penitenciario estipula que cada Centro tendrá un Consejo Técnico Interdisciplinario que diseñe e instrumente los programas destinados a las actividades de educación, trabajo, capacitación y salud. ${ }^{22}$ De acuerdo a esta ley, los centros contarán con un lugar apropiado, así como con personal capacitado, mobiliario, instrumental y productos farmacéuticos, para proporcionar a los internos la asistencia médica necesaria. ${ }^{23}$ También dispone que los servicios médicos de los centros velarán por la salud física y mental de los internos y menciona las actividades que se procurarán para

\footnotetext{
${ }^{17}$ De acuerdo a entrevista realizada a custodia del Centro Estatal de Reclusión de la capital potosina

${ }^{18}$ Según entrevista realizada a personal del CEREDI en Santa María del Río.

${ }^{19}$ Información proporcionada por personal administrativo del CEREDI en Santa María del Río.

${ }^{20}$ Establecidos por la Organización de las Naciones Unidas el 17 de diciembre de 1971.

${ }^{21}$ BARROS LEAL, César op.cit., nota 8, p. 128.

${ }^{22}$ Artículo 29 de la ley del sistema penitenciario del Estado de San Luis Potosí.

${ }^{23}$ Artículo 49 de la ley del sistema penitenciario del Estado de San Luis Potosí.
} 
cumplir con el principio de la salud como medio de la reinserción social. En consecuencia, se percibe una franca desatención a la normatividad existente. ${ }^{24}$

Este mismo ordenamiento dispone que existirán establecimientos de tratamiento especial que formarán parte de los centros de reinserción para un debido tratamiento psiquiátrico de enfermos mentales encausados penalmente. ${ }^{25}$ Asimismo, al área psiquiátrica corresponderá detectar y tratar las enfermedades mentales y emocionales de los internos, sobre todo cuando representen una amenaza para su propia integridad física, la de terceros o la seguridad de los centros. En consonancia con lo anterior, el Reglamento Interior de los Centros Estatales de Reclusión de San Luis Potosí señala como funciones de la Subdirección Médica coadyuvar con el área Psiquiátrica para el diagnóstico y tratamiento de internos con problemas de salud mental; los cuales serán atendidos en instalaciones adecuadas para tal efecto. ${ }^{26}$ Pese a ello, la investigación llevada a cabo revela que hay internos con problemas médicos como convulsiones y no se cuenta con este apoyo de especialistas. Bajo estas condiciones, no se garantiza el acceso al derecho a la salud, generando un ambiente que no es propicio para la reinserción.

Los internos tienen derecho a una alimentación sana. En este respecto, el Reglamento Interno para los Centros de Reclusión Distrital ${ }^{27}$ señala tres tiempos para la alimentación, ${ }^{28}$ no obstante como los CEREDIS están bajo la administración y mantenimiento de municipio correspondiente, éste se sujeta a las condiciones económicas del mismo. Para ejemplificar se menciona el caso de Santa María del Río en donde se llegan a cambiar los horarios de alimentación y no sirven cena. Ante este escenario, la mala alimentación en los centros penitenciarios dio lugar a que se presentara una iniciativa de reforma al artículo 8 de la Ley del Sistema Penitenciario del Estado de San Luis Potosí para que las autoridades sanitarias lleven a cabo en forma permanente, procesos de certificación de calidad, que garanticen los alimentos suministrados. La Comisión de Salud y Asistencia Social aprobó la iniciativa de reforma.

\section{EL TRABAJO, LA EDUCACIÓN Y DEPORTE EN LOS CENTROS DE REINSERCIÓN}

Los reclusos tienen derecho al trabajo. El trabajo es una actividad vital con sentido social reconocido por la Constitución Federal en sus artículos 5 y 123 el cual no puede ser coartado por la detención de que sea objeto un ser humano. Entre algunos datos importantes de la historia penitenciaria en México es importante señalar que el trabajo de los internos fue establecido en el artículo 18, segundo párrafo del Pacto Federal el cual dispone:

El sistema penitenciario se organizará sobre la base ... del trabajo... como medios para lograr la reinserción del sentenciado a la sociedad y procurar que no vuelva a delinquir, observando los beneficios que para él prevé la ley.

Fue en 1965 cuando además del trabajo se contempla la capacitación y la educación del prisionero. El artículo 10 de la Ley de Normas Mínimas estipula que para asignar trabajo

\footnotetext{
${ }^{24}$ Artículo 55 de la ley del sistema penitenciario del Estado de San Luis Potosí.

${ }^{25}$ Artículos 16 y 53 de la ley del sistema penitenciario del Estado de San Luis Potosí.

${ }^{26}$ Artículo 28 fracción XII del Reglamento Interior de los Centros Estatales de Reclusión de San Luis Potosí.

27 Artículo 58 del Reglamento Interno para los Centros Estatales de Reclusión de San Luis Potosí.

${ }^{28}$ Estos se dividen en el desayuno a las o8:00 a.m., de 13:30 a 14:30 horas la comida y descanso y de 18:00 a 18:30 p.m. la cena.
}

CienCIA JuRídica. Departamento de Derecho. División de Derecho, Política y Gobierno, Universidad de Guanajuato - Año 5, No. 9, 2016 
a los internos se tomará en cuenta los deseos, vocación, aptitudes y la capacitación laboral para la actividad productiva en libertad. Menciona además que el trabajo será opcional y no coercitivo. Ahora bien, para garantizar una infraestructura laboral penitenciaria es necesaria la participación de los distintos niveles de gobierno, en este respecto existirá la colaboración del juez de ejecución a quien se encomienda que estas actividades sean voluntarias y no coercitivas ni indignas.

Entre las razones de incorporar actividades laborales a los internos se encuentran que es una terapia ocupacional, disminuye la ansiedad y depresión, reorienta la reinserción del reo puesto que los dota de hábitos de disciplina colateral, fortalece el sustento de su familia puesto que está en condiciones de proveer económicamente, permite satisfacer necesidades materiales, posibilita la reparación de un daño a la víctima. Pues bien, la Ley del Sistema Penitenciario de San Luis Potosí contempla que el trabajo es un medio para conseguir la reinserción de los internos, como consecuencia, la actividad laboral de los reclusos tendrá que tener en cuenta sus aptitudes físicas y mentales y que no será tomada como un castigo sino como un tratamiento terapéutico y para su sostenimiento económico. ${ }^{29}$ Por su parte, el Código de Procedimientos Penales potosino dispone que siempre y cuando el interno demuestre buena y haya cumplido con la sanción pecuniaria, por cada dos días de trabajo, se hará la remisión de un día de prisión. No obstante, la situación actual es que aunque se ofrecen ocupaciones de plomería, carpintería, herrería, tortillería y panadería, no todos los internos trabajan. Se han tenido algunos avances pero aún falta brindar oportunidades de estudio y trabajo a los reclusos. Existen talleres de recreación que llevan a cabo manualidades en el caso de mujeres y se ofrece pintura y artesanía para los varones..$^{30}$

La educación es un factor primordial para la reinserción del interno y comprenderá aspectos no meramente académicos sino también cívicos, sociales, artísticos, deportivos, éticos y de higiene. La ley del sistema penitenciario en el Estado establece la obligatoriedad de la primaria y secundaria y el propósito de impartir educación preparatoria o técnica en los centros de reinserción. ${ }^{31}$ Atendiendo al desarrollo humano de los internos, se promoverán conferencias, veladas literarias, funciones de teatro, conciertos. En este tenor y debido a que los internos tienen derecho a participar en los programas educativos, alfabetización, primaria, secundaria, preparatoria, universidad y posgrado se invita al Instituto Nacional de Educación de los Adultos INEA a dar de alta a los internos que quieran terminar sus estudios de primaria, secundaria y preparatoria siendo decisión propia el terminar sus estudios. Aun así, otro aspecto que prevalece es que son muy pocos los internos interesados en la educación. En el centro penitenciario de la capital potosina se encuentra una biblioteca pequeña pero no la visitan los internos.

Por lo que atañe al deporte, la ley del sistema penitenciario de San Luis Potosí dispone que los centros fomentarán la participación de los internos en programas de acondicionamiento físico, el cual debe cumplir dos funciones, la preventiva, y la recreativa, como parte del cuidado de la salud del interno y de su programa de reinserción. ${ }^{32}$ Para ello, se prevé fomentar la actividad deportiva de los internos y dar cursos de capacitación deportiva, además de realizar campañas para conocer la importancia del deporte y ofrecer programas deportivos acordes con sus condiciones físicas y estado de salud.

\footnotetext{
${ }^{29}$ Artículo 41 de la Ley del Sistema Penitenciario de San Luis Potosí.

30 Según entrevista realizada a personal del CERESO en Matehuala, San Luis Potosí.

${ }^{31}$ Artículo 47 de la ley del sistema penitenciario en el Estado de San Luis Potosí.

${ }^{32}$ Artículo 54 de ley del sistema penitenciario del Estado de San Luis Potosí.
} 


\section{AUTOGOBIERNO, RIÑAS Y MOTINES}

Existe el autogobierno. Los custodios o incluso el personal administrativo de los penales son partícipes de las extorsiones y el cobro del derecho de piso. El cobro por el pase de lista a los internos, la autorización y renta de áreas conyugales, la administración de las tienditas, el suministro de drogas, el contrabando de todo tipo de mercancías se traduce en una fuente de ingresos. Las redes de corrupción y la actividad ilícita intramuros evidencian control por el crimen organizado el cual está infiltrado en los centros penitenciarios del Estado. En efecto, en los centros penitenciarios de San Luis Potosí como de otros estados de la República son grupos de internos los que ejercen el control del establecimiento, imponen su ley y coadministran el penal. ${ }^{33}$

No podemos dejar de mencionar la serie de hechos de violencia que incluyen reyertas, ejecuciones, "suicidios" y linchamientos en los distintos penales de San Luis Potosí. Entre estos se registra que:

- El 20 de enero de 2010 en el Centro Estatal de Reclusión de San Luis Potosí se reportaron disturbios que dieron por consecuencia 23 fallecidos.

- El 12 de febrero de 2011, en el interior del Centro de Internamiento Juvenil se originó una protesta violenta por parte de los jóvenes internos a causa de que los Directivos no atendieron algunas peticiones. Para restaurar el orden, se convocó a las fuerzas policiales, como elementos de Seguridad y Custodia del Centro Estatal de Reinserción Social de San Luis Potosí, lo que suscitó un enfrentamiento entre los agentes de autoridad y los jóvenes internos cuyo resultado fue de 39 jóvenes lesionados y destrozos en el interior del CIJ. ${ }^{34}$

- 30 de marzo 2011 ocurrió una riña en las instalaciones del centro penitenciario de la capital potosina, donde resultaron lesionados ocho reos. Menos de 24 horas después del evento, el subdirector del Penal de La Pila, fue ejecutado.

- El 8 de julio de 2011 se desató una riña en centro penitenciario de la capital potosina

- El 27 de abril del 2013 se registró una riña entre reclusos del Centro Estatal de Reinserción Social de la Pila en la capital potosina dejando 13 internos muertos y 65 heridos.

- El 21 de diciembre del 2015 se causaron destrozos, saqueos e incendios en diversas áreas dejando heridos después de un motín que enfrentó a grupos antagónicos.

\section{REFORMAS AL SISTEMA PENITENCIARIO MEXICANO}

La regulación de estos desafíos, ha ido avanzando paulatinamente. Se originaron algunos progresos en 1965 cuando se publicó el primer decreto que reforma y adiciona el artículo 18 constitucional humanizando el modelo penitenciario de nuestro país. ${ }^{35}$ Es entonces cuando

\footnotetext{
${ }^{33}$ De acuerdo al diagnóstico nacional de supervisión penitenciaria, elaborado por la Comisión Nacional de Derechos Humanos en 2011.

${ }^{34}$ Reporte proporcionado por la Tercera Visitadora de la Comisión Estatal de Derechos Humanos Lic. Begoña Castillo Martínez.

${ }^{35}$ RIVERA MONTES DE OCA, Luis, Juez de Ejecución de Penas, Editorial Porrúa, México, 2003, p 25- 27. 
se incorpora el trabajo, la capacitación laboral y la educación, como base de la readaptación del delincuente. Con éste, se estipula que los gobiernos estatales y la federación podrán celebrar convenios para que los reos sentenciados por delitos del orden común extingan su condena en establecimientos dependientes del Ejecutivo Federal. La reforma de 1977 permitió que reos mexicanos internos en el extranjero pudieran ser trasladados a México a compurgar sus condenas, de la misma forma que los reos extranjeros pueden ser trasladados a su lugar de origen. Y en este contexto, es hasta el 2001 que se permite que los sentenciados puedan cumplir sus penas en los centros penitenciarios más cercanos a su domicilio. Además de dichas modificaciones al Pacto Federal, se obtuvo un logro importante en 1971, fecha en que se promulga la Ley que Establece las Normas Mínimas sobre Readaptación Social de Sentenciados la cual tenía como propósitos principales lograr una coordinación entre el Ejecutivo Federal y estados de la República para el mejoramiento de la administración carcelaria y la optimización de recursos humanos y materiales. Asimismo clasifica los beneficios de la libertad anticipada y otras bondades como el tratamiento preliberacional y la remisión parcial de la pena. Con esta ley, correspondía a la Dirección General de Servicios Coordinados de Prevención y Readaptación Social aplicar las normas a los reos sentenciados fueran del fuero federal o del fuero común para el entonces Distrito Federal.

De forma más reciente, el 18 de junio del 2008 se publica en el Diario Oficial de la Federación la reforma en materia de justicia penal y seguridad pública en la que se modifican los artículos 18 y 21 y otros ocho numerales más. ${ }^{36} \mathrm{El}$ artículo 18 regula el sistema penitenciario además de establecer el sistema de reinserción social, mientras que el segundo establece la competencia exclusiva del poder judicial sobre la imposición, modificación y duración de las sanciones penales. En consonancia con la reforma constitucional en materia de derechos humanos del 10 de junio del 2011 el mismo numeral 18 de la Ley Fundamental estipula que el sistema penitenciario se organizará sobre la base del respeto a los derechos humanos, además del trabajo, la capacitación para el mismo, la educación, la salud y el deporte como medios para lograr la reinserción del sentenciado a la sociedad.

Teniendo en cuenta la reforma constitucional del 10 de junio del 2011 en la que los derechos consagrados por tratados internacionales adquieren un carácter constitucional, resulta primordial enunciar algunas convenciones que regulan aspectos de derecho penitenciario, a las que México se ha adherido. En cuanto a la sobrepoblación penitenciaria, las Reglas Mínimas de las Naciones Unidas para el Tratamiento de los Reclusos, ${ }^{37}$ ratificada por México, establecen que: "las celdas o cuartos destinados al aislamiento nocturno no deberán ser ocupados más que por un solo recluso” Por otra parte, las Reglas Mínimas de las Naciones Unidas para la Administración de Justicia de Menores, ${ }^{38}$ ratificada por México, establece que: "en la ejecución efectiva de la resolución, las autoridades juzgadoras adoptarán ellas mismas disposiciones adecuadas para la ejecución de sus órdenes". Como se mencionará posteriormente, con la creación del juez de la ejecución de las penas en México, se propone adaptar su legislación interna a los lineamientos establecidos en el ámbito internacional. El Manual de Buena Práctica Penitenciaria conocido como Implementación de las Reglas Mínimas de

\footnotetext{
36 También se reforman los artículos 16, 17, 19, 20, 22 las fracciones XXI y XXIII del artículo 73, la fracción VII del artículo 115, y la fracción XIII del apartado B del artículo 123 Constitucional.

37 Promulgada en 1955.

${ }^{8}$ Aprobada y proclamada en la 96 sesión plenaria de la Asamblea General de la ONU el 28 de noviembre de 1985.
} 
Naciones Unidas para el Tratamiento de los Reclusos ${ }^{39}$ dispone que las violaciones de los centros reclusorios incluyen el derecho a la vida; a la seguridad de la persona; el derecho a no ser torturado o maltratado; el derecho a la salud; el derecho al respeto de la dignidad humana; el derecho a un juicio justo; el derecho a la no-discriminación de ningún tipo; el derecho a no ser sometido a esclavitud; el derecho a la libertad de conciencia y pensamiento; el derecho a la libertad de culto; el derecho al respeto de la vida familiar y el derecho al desarrollo personal. Por su parte, la Convención Interamericana para Prevenir y Sancionar la Tortura ${ }^{40}$ estipula que "ni la peligrosidad del detenido o penado, ni la inseguridad del establecimiento carcelario o penitenciario pueden justificar la tortura". Asimismo, también señala que los Estados tomarán medidas para que los funcionarios responsables de la custodia de las personas privadas de su libertad, provisional o efectiva, pongan especial énfasis en la prohibición del empleo de la tortura. La Convención Interamericana sobre asistencia mutua en materia penal ${ }^{41}$ regula la asistencia jurídica internacional y compromete a los Estados parte a brindarse asistencia mutua en investigaciones, juicios y actuaciones en materia penal referentes a delitos cuyo conocimiento sea de competencia del Estado requirente al momento de solicitarse la asistencia y la Convención contra la Delincuencia Organizada Transnacional también conocida como Convención de Palermo ${ }^{42}$ a pesar de ser un instrumento para abatir el crimen organizado señala que en todas las actuaciones se garantizará un trato justo a toda persona contra la que se haya iniciado una instrucción en relación con cualquiera de los delitos a los que se aplica la extradición, incluido el goce de todos los derechos y garantías previstos por el derecho interno del Estado Parte en cuyo territorio se encuentre esa persona. ${ }^{43}$ Finalmente, entre otros documentos y convenciones que establecen que la privación a la libertad sea respetuosa de los derechos humanos se encuentran la Declaración Universal de los Derechos Humanos, la Convención Americana de Derechos Humanos, el Pacto Internacional de Derechos Económicos, Sociales y Culturales, la Convención Internacional contra la Tortura y Otros Tratos o Penas Crueles, Inhumanos o Degradantes.

\section{REFORMA LEGISLATIVA EN MATERIA DE EJECUCIÓN PENAL EN MÉXICO}

En este proceso de cambio, también se reforma el artículo 73 fracción XXI de la Constitución Federal con el objeto de dar facultades al Congreso de la Unión para expedir legislación única en materia de ejecución de penas y de justicia penal para adolescentes, que regirá en el país en el orden federal y fuero común. ${ }^{44}$ Esta ley todavía no se promulga, sin embargo su propósito es incluir la figura del Juez de Ejecución la cual se ha vislumbrado como una alternativa ante esta necesaria organización en los establecimientos penitenciarios, espacios en los que se violan fehacientemente los derechos humanos. El Juez de Ejecución Penal es un funcionario del poder judicial dedicado a vigilar la ejecución de las penas y medidas de seguridad y a controlar la actividad penitenciaria, buscando garantizar los derechos de

\footnotetext{
39 Instituto Interamericano de Derechos Humanos en San José Costa Rica, 1998.

40 Aprobada por la Asamblea General de la Organización de Estados Americanos (OEA) el 6 de diciembre de 1985 .

${ }^{41}$ Ratificada el 7 de enero y publicada en el DOF el 2 de abril del 2003.

42 Aprobada el 22 de octubre y publicada en el DOF el 2 de diciembre del 2002.

43 Artículo 16 de la Convención.

44 Publicado en el DOF el 2 de julio del 2015. 
los internos".45 Se ha vislumbrado al juez de vigilancia penitenciaria como una respuesta al estado de crisis que se vive en los centros carcelarios, en este sentido se pretende que sea una autoridad competente para resolver sobre los beneficios, el tratamiento, la extinción de las penas y medidas de seguridad así como para modificar la duración de una pena basándose en el comportamiento del condenado. Asimismo, entre sus funciones está llamado a monitorear el tratamiento que se le imponga para su reinserción social y a ser garante de la legalidad en los criterios jurídicos y criminológicos.

Uno de los principales problemas que se han presentado en las diferentes entidades federativas que han incorporado esta figura del Juez de Ejecución es que éste se involucra en aspectos técnicos, operativos y administrativos que corresponden a los centros penitenciarios. El homólogo en el estado de San Luis Potosí tiene funciones de vigilancia pero no es potestad de la autoridad penitenciaria. A este juez le compete la entrega del prisionero a sus familiares cuando corresponda y de sujetos inimputables de baja peligrosidad. Para ello se proyecta la realización de estudios de personalidad ${ }^{46}$ que determinen la peligrosidad de un sujeto inimputable no siendo suficiente únicamente la opinión del médico perito. En otras palabras, es necesario realizar un estudio en que colaboren psicólogos, trabajadores sociales, pedagogos, médicos y psiquiatras que determinen, a través de un estudio integral, el peligro que representa para la sociedad. Se establece asimismo, que el juez de seguimiento a los individuos que hayan cumplido su sentencia y obtenido su libertad para lo cual monitoreará su comportamiento al menos por un año, razón por la cual deberá conocer sus actividades y su domicilio. Si se trata de un individuo responsable de un delito grave, el juez impondrá medidas de vigilancia cuando obtenga su libertad. Una vez promulgada la Ley Nacional de Ejecución de Sanciones será ésta quien recoja estas funciones encargadas a la autoridad judicial, este es un trabajo legislativo pendiente del que se anticipa su próxima promulgación.

Con la intención de hacer estos cambios posibles, se implementaron reformas legislativas. A manera de antecedente, es digno mencionar que en San Luis Potosí se reformó el Código de Procedimientos Penales del Estado adicionando numerales para hacerlo más compatible con la Ley Orgánica del Poder Judicial y la Ley del Sistema Penitenciario, en materia de ejecución de sentencias. Con apego a la reforma constitucional del 2008 en San Luis Potosí se estudió la posibilidad de crear un Código de Ejecución, previendo no afectar la estructura administrativa ya existente. El código no fue creado en estas fechas por lo que se reformó la ley adjetiva penal que fuera sustituida por el Código Nacional de Procedimientos Penales, ley vigente a partir del 30 de septiembre del 2014 en algunos distritos judiciales del estado para delitos del orden común y a partir del 1 de agosto del 2015 en delitos del fuero federal. También se modifica la Ley Orgánica de la Administración Pública del Estado, la Ley Orgánica del Poder Judicial del Estado y el Código Penal del Estado para coordinar las autori-

\footnotetext{
${ }^{45}$ MORENO VARGAS, Mauricio, Nuevo Sistema de Justicia Penal para el Estado de México, Editorial Porrúa, México, 2010.

${ }^{46}$ Se denominan estudios de personalidad a los evaluaciones practicadas por el Consejo Técnico Interdisciplinario en las áreas, médica, psicológica, psiquiátrica, educativa, criminológica, social, ocupacional, y de vigilancia. El Reglamento de los Centros Estatales de Reclusión señala que debe de existir un Consejo Técnico Interdisciplinario el cual está integrado por el Director y todas las Subdirecciones del Centro en donde se evalúa la vida cotidiana (conducta, criminológico, laboral, médico y seguridad) de la persona privada de su libertad en el período de su reclusión.
} 
dades que participan en el sistema de justicia penal y de seguridad pública. En este sentido, surge la reforma al sistema Penitenciario del Estado de San Luis Potosí.

La Ley del Sistema Penitenciario del Estado de San Luis Potosí constituye un avance ante una problemática de las prisiones del estado. Esta ley se orienta hacia una función resocializadora de la pena que se traduce en mantener un núcleo humanístico y humanitario, durante el cumplimiento de la condena. ${ }^{47}$ Sin embargo, esto se logra de la mano de la aplicación de políticas sociales que favorecen la re-integración de aquellos que han cumplido alguna pena privativa de libertad. Como dice Rubio, la pena se justifica en la medida que se proteja a la sociedad contra el crimen aprovechando el período de privación de libertad para lograr que el delincuente una vez liberado, no solamente quiera respetar la ley y proveer sus necesidades, sino que sea capaz de hacerlo. ${ }^{48}$ Es así que referida ley establece, ordena y estructura el sistema penitenciario que considera y pondera la reinserción del sentenciado, como resultado del trabajo, la educación, la salud, el deporte, la disciplina y el respeto a los derechos humanos.

De acuerdo a la reforma del 2011, el Código de Procedimientos Penales del Estado ${ }^{49}$ dispone que es competencia exclusiva de los Tribunales del Estado en materia penal, imponer a los responsables las penas y medidas de seguridad establecidas en las leyes penales y determinar sobre su modificación y duración. Asimismo, señala que la ejecución de las penas y medidas de seguridad se realizará una vez que la sentencia haya causado ejecutoria y que se desarrollará con las garantías y sujeción a lo establecido en el Pacto Federal, los tratados internacionales y las demás leyes aplicables. ${ }^{50} \mathrm{El}$ código establece que el sentenciado que esté en condiciones de recibir los beneficios de la suspensión condicional o sustitución de la pena podrá solicitarlos al Juez de Ejecución en caso de no haber obtenido una sentencia que otorgara dichos beneficios y correspondiendo a este juez cuidar el debido cumplimiento de estas penas. Además dispone que este funcionario judicial examinará periódicamente la situación de los sentenciados que cumplen una medida de seguridad y de acuerdo a los exámenes que se realizaran se podría cesar o continuar la medida, caso en el cual podrá ordenar la modificación del tratamiento. En caso de que se establezca un tratamiento en libertad, trabajo a favor de la comunidad, el juez es quien establece las modalidades para su ejecución. También aborda la concesión del tratamiento preliberacional por el juez de ejecución y las condiciones para recibirlo.

Preparando la armonización con referida normatividad que incorpora a los juzgados de ejecución, la Ley Orgánica de la Administración Pública del Estado de San Luis Potosí establece que a la Secretaria de Seguridad Pública le corresponde administrar el sistema penitenciario; aplicar el modelo de reinserción social y tramitar por acuerdo del Gobernador del Estado las solicitudes de extradición y traslado de internos. ${ }^{51}$ Señala también que cualquier disposición respecto de las funciones desempeñadas por la Secretaría General de Gobierno, en materia de prevención y reinserción social, así como del sistema de menores infractores,

47 LEAL, Luisa, y GARCÍA, Adela, "Programa de reinserción Social como Mecanismo Rehabilitador de la Pena, Un Estudio de la Región Occidental Zuliana”, Capítulo Criminológico, año 35, No 3, 2007, p. 357.

${ }^{48}$ RUBIO HERNÁNDEZ, Herlinda Enríquez, "La prisión. Reseña histórica y conceptual", Ciencia Jurídica, Universidad de Guanajuato. División de Derecho, Política y Gobierno. Departamento de Derecho, Año I, No. 2, p. 24.

${ }^{49}$ Fracción IV del artículo 4 del Código de Procedimientos Penales del Estado de San Luis Potosí.

${ }^{50}$ Numeral 481 del Código de Procedimientos Penales del Estado de San Luis Potosí-

${ }^{51}$ Fracción XXXI del artículo 41 quater de la Ley Orgánica de la Administración Pública del Estado de San Luis Potosí reformado el 28 de marzo del 2012. 
se entenderán ahora referidas a la Secretaría de Seguridad Pública a la cual se han transferido, hasta en tanto se lleven a cabo las adecuaciones correspondientes.

Este ordenamiento dispone que a la Secretaria de Seguridad Pública le corresponde vigilar y coordinar, a través de la Dirección de Ejecución de Medidas para Menores, el funcionamiento de los centros de internamiento juvenil y de los centros de ejecución de medidas en libertad; así como elaborar los programas personalizados de ejecución y ejecutar las medidas de internamiento definitivo dictadas por el Juez Especializado en Justicia para Menores. ${ }^{52}$

En el mismo orden, el artículo tercero transitorio de los decretos de reformas a esta ley señala que la situación jurídica de las personas que estén compurgando una pena de prisión, por haber cometido un delito siendo menores de dieciocho años, será resuelta sobre la base de las reformas al artículo 18 del Pacto Federal. En este contexto, el juez penal que conoció de la causa, remitirá el expediente al juez de ejecución para que resuelva lo procedente.

En consonancia con estas reformas, la Ley Orgánica del Poder Judicial del Estado de San Luis Potosí, se modifica el 1 agosto del 2013 y establece que el Poder Judicial del Estado se integra por Juzgados de Ejecución de Sentencia. ${ }^{53}$ También contempla a los jueces de ejecución especializados en justicia para menores y establece que sus atribuciones son resolver la modificación, sustitución o adecuación de las medidas impuestas a menores, determinar las medidas coercitivas aplicadas a menores en los centros de internamiento y autorizar los convenios de colaboración que firme la Dirección General de Ejecución de Medidas para Menores, los Centros de Internamiento Juvenil y los Centros de Ejecución de Medidas en Libertad, entre otras. ${ }^{54}$

Como ya se mencionó, el Código de Procedimientos Penales queda abrogado por el Código Nacional de Procedimientos Penales en algunos distritos judiciales no siendo aplicable en Matehuala, Ciudad Valles, Rioverde, Tamazunchale y Tancanhuitz en donde el Código Nacional de Procedimientos Penales es derecho vigente. El Código Nacional no hace referencia al juez de ejecución, sin embargo, esta figura es regulada por la Ley de Ejecución de medidas cautelares, penas y medidas de seguridad del estado potosino. Por su parte, en la capital potosina se seguirá aplicando el Código Procesal Penal del Estado hasta el 31 de marzo del 2016. Desafortunadamente, en la capital potosina están retrotrayendo el Código Procesal Penal en relación a beneficios preliberaciones, teniendo una actitud regresiva y contraria a la intención del legislador cuando estipular estos cambios.

El cambio más reciente en esta materia es la Ley de Ejecución de Medidas Cautelares; penas y medidas de seguridad para el Estado de San Luis Potosí publicada el 29 de septiembre del 2014 cuyo objeto es establecer bases para la coordinación entre autoridades judiciales administrativas y entidades de derecho privado, en materia de ejecución y vigilancia de penas y medidas de seguridad impuestas mediante sentencia firme..$^{55}$ Esta nueva ley tiene como objetivo actualizar la legislación en la materia y armonizarla con lo establecido en el artículo octavo transitorio del Código Nacional de Procedimientos Penales que contempla la expedición de la legislación complementaria, necesaria para la implementación del sistema acusatorio. Atiende a la necesidad de contar con una legislación acorde a este modelo el

\footnotetext{
${ }^{2}$ Fracción XXXII del artículo 41 de la Ley Orgánica de la Administración Pública del Estado de San Luis Potosí adicionada el 28 de marzo del 2012.

${ }^{53}$ Artículo 4 de la Ley Orgánica del Poder Judicial del Estado de San Luis Potosí.

54 Artículo 53 Ter de la Ley Orgánica del Poder Judicial del Estado de San Luis Potosí.

${ }^{55}$ Con esta ley se abroga la Ley de Ejecución de Penas y Medidas de Seguridad del Estado de San Luis Potosí que fuera publicada en el Periódico Oficial del Estado, en el Decreto Legislativo número 572 del dieciocho de junio de 2011.
} 
cual entró en vigor el 30 de septiembre del mismo año en el segundo distrito judicial. A este juez corresponderá el otorgamiento o denegación de cualquier beneficio relacionado con las penas o medidas de seguridad impuestas en la sentencia firme. ${ }^{56}$ Los beneficios de libertad anticipada que serán otorgados por el Juez de Ejecución son el tratamiento preliberacional, la libertad preparatoria y la remisión parcial de la pena ${ }^{57}$ los cuales se otorgarán siempre y cuando no se haya cometido un delito que merezca prisión preventiva y que en este sentido sea señalado por el Código Nacional de Procedimientos Penales. ${ }^{58}$

Aun cuando se prevean estos cambios en la norma adjetiva y aunque después de la publicación de estas reformas se implementaron visitas carcelarias por parte del funcionario judicial, la excesiva carga de trabajo ha dado lugar a otro escenario pues al año se cuenta con más de mil expedientes. Actualmente, el juez de ejecución toma conocimiento de los casos siempre y cuando la defensa interponga queja. Además en virtud de que el sistema penal acusatorio entrará en vigor hasta el 31 de marzo del 2016 en la capital potosina, las audiencias en esta materia todavía no son públicas y estas tienen lugar a menos que los internos hagan una solicitud de audiencia para atender los reclamos que formulen sobre sanciones disciplinarias, previo informe de la autoridad responsable o bien para resolver las peticiones o planteamientos de las partes, relativos a la revocación de cualquier beneficio concedido a los sentenciados por cualquier autoridad jurisdiccional, o bien para sobre libertad anticipada, libertad preparatoria, remisión parcial de la pena o libertad definitiva. Para ello se gira oficial al Director General de Prevención y Reinserción Social..$^{59}$ Esto conlleva retrasos en las solicitudes de los internos.

\section{DESAFÍOS EN LA NORMATIVIDAD PUNITIVA}

Como se ha expuesto, el objetivo principal de las reformas adoptadas ha sido en lo atinente a judicializar lo concerniente a la ejecución y cumplimiento de sanciones penales la cual será una facultad compartida entre el ejecutivo y el judicial, atribuciones que venía realizando el poder Ejecutivo a través de la Dirección General de Prevención y Readaptación Social. Esta reforma recoge la función y la toma de decisiones que tenía el poder ejecutivo en cuanto al cumplimiento de las sentencias del reo. Luego entonces, el poder legislativo determina el grado de control que seguirá teniendo la autoridad penitenciaria y le resta poder al ejecutivo estatal, siendo su función meramente administrativa, eliminando de su poder las facultades que ahora se le atribuyen a la figura del Juez de Ejecución. Este, es un actor que si bien viene a coadyuvar en la problemática, no es el único sujeto forjador del cambio ante este panorama de crisis en el país.

Pese a estas modificaciones legislativas, hay situaciones que no han sido abordadas por la norma jurídica. Específicamente, una cuestión que debe ser atendida para la mejor operatividad de estos centros son los reglamentos que rige a los CEREDIS ya que en ellos existen lagunas. A razón de ello, sus autoridades y personal recurren a la ley del sistema penitenciario en el estado de San Luis Potosí resultando que esta última no se puede aplicar porque es de

\footnotetext{
${ }^{56}$ Artículo 11 fracción III de la Ley de Ejecución de Medidas Cautelares; penas y medidas de seguridad para el Estado de San Luis Potosí.

57 Artículo 67 de la Ley de Ejecución de Medidas Cautelares; penas y medidas de seguridad para el Estado de San Luis Potosí.

${ }^{58}$ Artículo 167 del Código Nacional de Procedimientos Penales.

59 De acuerdo a entrevista realizada a defensores adscritos juzgado de ejecución de penas y medidas de seguridad.
} 
competencia estatal. Sin duda, otro reto es obtener un mayor apoyo gubernamental a los CEREDIS pues la carencia de fondos afecta la infraestructura y funcionalidad de estos lugares.

Otra área importante que no se desarrolla en la legislación aprobada es la obligación de realizar estudios de peligrosidad para sujetos inimputables. Se dispone que la buena conducta de un interno se evaluará a través del cumplimiento de los reglamentos del centro de reinserción, del mejoramiento en sus hábitos sociales y culturales, de sus estudios, de la superación en las actividades laborales y de la buena convivencia interna. En este respecto cabe señalar que la ley del sistema penitenciario en comento no señala la necesidad de realizar informes psicológicos del prisionero, entendiendo por tal el documento escrito donde se presentan los resultados de las exploraciones efectuadas, a partir de las cuales se realizan recomendaciones concretas o se derivan determinados tratamientos. ${ }^{60}$ El artículo 27 de la Ley del Sistema Penitenciario del Estado estipula que el personal técnico de la institución llevará a cabo el análisis integral de personalidad tomando en cuenta aspectos criminológicos, médicos, psicológicos, socioeconómicos, pedagógicos y laborales. ${ }^{61}$ Sin embargo, es oportuno que, con la intención de reinsertar al interno, colaboren psicólogos a través de estudios de peligrosidad quienes puedan comunicarle al Juez de Ejecución, en base a evaluaciones o diagnósticos, los resultados obtenidos y recomienden posibles tratamientos que puedan recibir los internos.

Una reforma integral y moderna en sistema penitenciario contemplaría la privatización carcelaria, o la tercerización (outsourcing) en donde se otorga a un privado la responsabilidad de otorgar el servicio de salud o seguridad en los penales. También incluiría las prisiones abiertas y la ayuda post-penitenciaria que consiste en un programa de reinserción laboral que proporciona a ex presidiarios el desarrollo de competencias para el empleo, capacitación y gestiones de colocación laboral dependiente. Estas son medidas que se orientan hacia una política penitenciaria más humana que sin duda involucra no únicamente a las autoridades estatales sino a los miembros de la comunidad en que se gesta la criminalidad. Recordemos como fuera estipulado en las Reglas Mínimas del Tratamiento a Reclusos: "el deber de la sociedad no termina con la liberación del recluso" es por ello que se deben de formular políticas, planes y programas para el tratamiento y rehabilitación del reo encaminados a reincorporarlo al tejido social. Es en esta vertiente que creemos que entre uno de estos cambios será contemplar a la sociedad civil en estas políticas debido a que sociedad no debe ser ajena a estos modelos puesto que el delito se gesta en y afecta a la comunidad misma.

En suma, las reformas a la ley penal -en este caso al derecho penitenciario- deben abordar los problemas penales expuestos, pues como puntualmente manifiesta Vidaurri, si la ciencia penal no propone soluciones racionales e inteligentes a los problemas penales, sería una ciencia inútil o estéril. ${ }^{62}$

\section{CONCLUSIONES}

El tratamiento en los centros penales transgrede y niega los derechos fundamentales del hombre, el cual se había venido justificando porque se trata de personas que participaron en la comisión de un delito. Sin embargo, se olvida que un procesado no siempre es un

\footnotetext{
${ }^{60}$ FERnÁndeZ-BALlesteros, Rocío, Psicodiagnóstico, Madrid, Universidad Nacional de Educación a Distancia, 1983, p 41-78.

${ }^{61}$ Artículo 27 de la Ley del Sistema Penitenciario del Estado de San Luis Potosí.

${ }^{62}$ VIDAURRI ARÉCHIGA, Manuel, Teoría General del Delito, Oxford, México, 2013, p. 1.
} 
culpable y en forma regular queda estigmatizado como si su responsabilidad hubiera sido comprobada. En México, los legisladores se han inclinado por el agravamiento de las penas privativas de libertad no siendo éste el mejor camino para enfrentar la criminalidad. Política que disiente con Cesare Beccaria cuando expresara atinadamente en su obra: De los delitos y las penas "el castigo es muchas veces superior al crimen" y más tarde añadiera "los suplicios parecen haber sido inventados más bien por la tiranía que por la justicia”.

En este mismo contexto, se ha comenzado a entender que la represión no es la única respuesta a la criminalidad y que el derecho penal está limitado por los derechos fundamentales establecidos en la Constitución. Bajo este esquema, proporcionar una ejecución penal digna cuya finalidad sea resocializadora, que busque reeducar al delincuente con tratamientos adecuados, es solamente una medida de entre otras propuestas novedosas para que los derechos humanos de los reclusos sean respetados y tomados en cuenta. Ahora bien, ante estos cambios la pregunta es, ¿la figura del Juez de Ejecución, será la manera de mejorar el aparato penitenciario para proteger los derechos humanos, para garantizar la seguridad y la integridad de los internos?

La respuesta es que este cambio no es suficiente y que para un adecuado funcionamiento del sistema penitenciario es necesario entre otros aspectos que se especifiquen los requisitos para designar al personal que trabaja en los centros de reinserción y que tendrá que estar basado tanto en pruebas psicológicas como vocacionales. Resulta imperioso que los trabajadores de los centros asistan antes de ingresar a sus funciones y durante las mismas a cursos de formación y actualización de criminología, psicología y derechos humanos, entre otros. También resulta menester contar con el número adecuado de jueces de ejecución en el Estado ya que a la fecha no son suficientes y aunado al número de jueces se debe contemplar la capacitación a esta nueva figura y los canales de integración entre los jueces de ejecución y el personal administrativo de los Centros de Reiserción.

Como fue mencionado anteriormente, es necesario un mayor apoyo económico tanto a CERESOS como a CEREDIS. Asimismo, es necesario seguir trabajando para fortalecer los protocolos del sistema preventivo y penitenciario para evitar situaciones que pongan en riesgo la integridad física, porque es responsabilidad de las autoridades estatales y municipales el garantizar la protección de las personas detenidas ante la presunción de un delito de tal forma que el trato que reciban los internos sea menos transgresor de los valores inherentes al hombre.

\section{FUENTES}

BIBLIOGRÁFICAS

BARROS, César, La Ejecución Penal en América Latina a la luz de los Derechos Humanos. Viaje por los senderos del dolor, Editorial Porrúa, Naciones Unidas Ilanud, Facultad de Derecho Unam. México 2009.

COTE, Gustavo, "La necesidad de la pena, reflexiones a partir de los artículos 3 y 4 del código penal colombiano". Revista del Instituto de la Judicatura Federal, Bogotá, no.114, julio-diciembre 2007 . 
GARCÍA, Sergio, "En torno a la seguridad pública", en PEÑALOZA, Pedro José y GARZA SALINAS, Mario, (coordinadores), Los desafíos de la seguridad pública en México, Universidad Iberoamericana, UNAM, PGR, México, 2002.

LARA, Klahr, Marco Prisión sin Condena. Ocho historias sobre los costos sociales del encierro preventivo en México, Editorial Debate, México, 2008.

LEAL, Luisa, y GARCÍA, Adela, "Programa de reinserción Social como Mecanismo Rehabilitador de la Pena,Un Estudio de la Región Occidental Zuliana”, Capítulo Criminológico, año 35, No 3, 2007.

LUNA, José, La aplicación de las penas en México. Enfoque crítico desde la perspectiva de los principios constitucionales, Editorial Porrúa, México, 2010.

MORENO, Mauricio, Nuevo Sistema de Justicia Penal para el Estado de México, editorial Porrúa, México, 2010.

OCHOA, Roberto, La justificación de la pena, editorial Porrúa y Universidad Panamericana, México, 2010.

OJEDA, Jorge, Derecho de Ejecución de Penas, Editorial Porrúa, México, 1985.

RIVER, Luis, Juez de Ejecución de Penas, Editorial Porrúa, México, 2003.

RUBIO, Herlinda, "La prisión. Reseña histórica y conceptual”, Ciencia Jurídica, Universidad de Guanajuato. División de Derecho, Política y Gobierno. Departamento de Derecho. Año I, no. 2, 2012.

RUIZ, Mariano, La Crisis de la Prisión, Montero Editor, La Habana, 1949.

VIDAURRI, Manuel, Teoría General del Delito, Oxford, México, 2013.

\section{LEGISLACIÓN}

Código de Procedimientos Penales del Estado de San Luis Potosí reformado el 18 de junio del 2011.

Constitución Política de los Estados Unidos Mexicanos reformada el 18 de junio del 2008.

Ley del Sistema Penitenciario de San Luis Potosí del 10 de junio del 2011.

Ley Orgánica del Poder Judicial del Estado de San Luis Potosí reformada el 30 de junio del 2011.

Ley Orgánica de la Administración Pública para el Estado de San Luis Potosí reformada el 24 de junio del 2009.

Ley de Ejecución de Medidas Cautelares; penas y medidas de seguridad para el Estado de San Luis Potosí publicada el 29 de septiembre del 2014. 